\title{
ASSESSMENT OF SPERM MORPHOLOGY, CHROMATIN INTEGRITY, AND CATSPER GENES EXPRESSION IN HYPOTHYROID MICE
}

\author{
Fatemeh Alipour, ${ }^{1}$ Mehdi Jalali, ${ }^{1 *}$ Mohammad Reza Nikravesh, ${ }^{1}$ \\ Alireza Fazel, ${ }^{1}$ Mojtaba Sankian ${ }^{2}$ and Elnaz Khordad ${ }^{1}$ \\ ${ }^{1}$ Department of Anatomy and Cellular Biology, Faculty of Medicine, \\ Mashhad University of Medical Sciences, Mashhad, Iran \\ ${ }^{2}$ Bou-Ali Research Institute, Immunology Research Center, Mashhad University of Medical Sciences, \\ Mashhad, Iran
}

(Received: January 4, 2018, accepted: May 24, 2018)

\begin{abstract}
There is an evident relationship between the fertilizing capacity of sperm and the normal morphology, quality chromatin, and motility of sperm. It is well known that thyroid hormones are the important regulators of testicular function. A correlation was found between the hypothyroidism and sperm damages. The present study was conducted to investigate the effects of hypothyroidism on sperm morphology, chromatin quality, and motility. For this purpose, 20 male mice were divided into the control and the hypothyroid groups that received $0.05 \%$ 6- $n$-propyl-2-thiouracil (PTU) for 35 days. Sperm morphology with Papanicolaou staining and sperm chromatin quality with both Aniline Blue (AB) and Toluidine blue (TB) staining were assessed. Besides, immunohistochemistry and real-time PCR were performed to evaluate the changes of cation sperm channel (CatSper) genes. A significant increase in the sperm chromatin condensation was found in the hypothyroid mice compared to the control mice $(p<0.05)$. Furthermore, a significant decrease was observed in the morphology of normal sperm in hypothyroid mice compared to the controls $(\mathrm{p}<0.05)$. The results showed that Hypothyroidism could downregulate the expression of CatSper genes. Immunohistochemical data confirmed the real time-PCR results. Furthermore, the results showed that hypothyroidism could adversely affect sperm morphology, sperm chromatin condensation, and CatSper gene expression in mice and these abnormalities may be related to the excessive production of reactive oxygen species (ROS) in a hypothyroid state.
\end{abstract}

Keywords: hypothyroidism - sperm - chromatin - CatSper - testis

\section{INTRODUCTION}

Infertility is a widespread problem that affects approximately $15-20 \%$ of young couples. About $30-40 \%$ of all infertility cases are attributed to the male factors [24, 34]. Male infertility has many causes from hormonal imbalances to physical and psychological problems. Thyroid hormones are the important regulators of growth, development, and metabolism in most tissues of mammals [10, 30, 37, 41]. For many years, the male reproductive system has been regarded as an unresponsive organ to the thyroid hormone. However, the studies of the two recent decades have demonstrated that testis responses to the thyroid hormones [5, 40, 41]. It has been reported that thyroid hormones affect sperm motility. In a study, treating the semen samples with

\footnotetext{
*Corresponding author; e-mail address: JalaliM@mums.ac.ir
} 
thyroxine (T4) generated a significant increase in the percentage of hyperactive sperm $[19,41]$. Thyroid hormones increase the basal metabolic rate and oxygen consumption in sperm and increase the mitochondrial number and mitochondrial gene expression, which result in sperm motility $[6,17]$. Previous studies have revealed that thyroid dysfunction can lead to the morphological and functional abnormalities in the testis. Hypothyroidism as one the most common endocrine disorders has been reported to be associated with impairment in the percentage of live sperms, sperm numbers, sperm morphology, and sperm motility [9, 15, 16, 23, 37]. Several studies have shown that hypothyroidism decreases hyperactivated motility in sperm. Furthermore, a significant reduction has been observed in the progressive forward motility of sperm in the hypothyroid cases [3, 16, 17, 33, 37]. Sperm motility is considered to be one of the best predictors of fertilizing ability. Sperm in the epididymis displays a low-amplitude symmetrical tail motion, soon after sperm enters the Fallopian tubes, where they change into a high-amplitude asymmetrical tail bending called hyperactivation. Hyperactivated motility is necessary for sperm to penetrate the egg and deliver its genetic material [1, 2, 8, 12, 29, 35]. Calcium ions play a vital role in the hyperactivated motility of sperm and a sperm-specific cation channel (CatSper) mediates calcium influx into the sperm cytosol. The four members of this family are solely expressed in the testis and specifically localized to the sperm plasma membrane $[8,13,27,36]$. The CatSper channel is comprised of four $\alpha$-subunits (CatSper 1-4) and accessory subunits including $\beta, \gamma, \delta$, and $\varepsilon$. CatSper 1 and CatSper 2 are required for the regulation of the hyperactivated motility and male fertility. Several correlations between the CatSper genes and sperm motility have been reported in the previous studies $[27,28,35,36]$. Besides, today, it is well known that the quality of sperm chromatin can be a good biomarker in the evaluation of the male fertility potential. During spermatogenesis, sperm chromatin is tightly compacted by replacement of histones with protamines, and this nuclear compaction preserves sperm DNA from external damages such as oxidative stress [26, 30, 31, 39]. Oxidative stress known as one of the important causes of male infertility arises from exposure to high levels of reactive oxygen species (ROS). In this regard, the spermatozoa are highly vulnerable to excessive oxidative damage due to high contents of polyunsaturated fatty acids and a low antioxidant capacity. According to previous studies, thyroid hormone regulates oxygen consumption in testis and is important in preserving the balance between ROS and intrinsic antioxidant molecules of the testis. ROS as by-products of tissue metabolism is normally scavenged by physiological antioxidants defense systems. In reproductive system, intrinsic antioxidants maintain the functional integrity of the cell membrane, spermatogenesis, sperm morphology, and motility $[7,11,31,32]$. There are increasing bodies of evidence that show hypothyroidism is associated with the high production of ROS in testis. It is well known that high amounts of ROS negatively affect the quality of sperm DNA as well as sperm morphology and motility [11,22, 31, 32, 38]. This study was conducted to determine the effect of hypothyroidism on the alteration of sperm chromatin, sperm morphology, and CatSper 1 and CatSper 2 genes expression. 


\title{
MATERIALS AND METHODS
}

\begin{abstract}
Animals
In this experimental study, 20 male Balb/C mice with an age of about 9 weeks (20-25 g body weight) were obtained from the experimental animal house of Mashhad University of Medical Sciences (MUMS), Mashhad, Iran. The animals were maintained in special cages with a controlled temperature of $22-24{ }^{\circ} \mathrm{C}$ and a humidity of $50-55 \%$ with $12 \mathrm{~h}$ dark/light cycle throughout the experiments. Animals were fed with standard rodent pellets and drinking water ad libitum. All experimental protocols were performed in accordance with the animal laboratory guidelines of Mashhad University of Medical science, Mashhad. Iran. The animals were randomly divided into two groups $(n=10)$ : (1) the control group without any intervention and (2) the hypothyroid group administrated with $0.05 \%$ 6- $n$-propyl-2-thiouracil (PTU) through the drinking water for 35 days [7].
\end{abstract}

\section{Thyroid hormones measurement}

At the end of treatment period, each animal per group was anesthetized with chloroform and the blood samples were taken from the heart and then centrifuged to obtain sera. The levels of T4 and TSH in each serum were measured using chemiluminescent immunoassay [3].

\section{Epididymal sperm smear preparation}

The animals were sacrificed by the cervical dislocation then cauda epididymis removed and cut into small pieces, incubated in $1 \mathrm{ml}$ normal saline at $37{ }^{\circ} \mathrm{C}$ in $5 \%$ $\mathrm{CO}_{2}$ for $30 \mathrm{~min}$ to allow the sperm to disperse into the medium. Next, $10 \mu \mathrm{l}$ of sperm suspension was pipetted onto a slide, air dried, and fixed in methanol $70 \%$.

\section{Assessment of sperm chromatin quality}

To assess spermatozoa chromatin condensation, Aniline blue (AB) and Toluidine blue (TB) staining were performed.

\section{Aniline blue $(A B)$}

Aniline blue is an acidic dye that indicates the residual histones in the chromatin structure. To carry out this staining technique, after smearing of epididymal sperm, the slides were first washed with distilled water for $3 \mathrm{~min}$, followed by staining with 
the $5 \% \mathrm{AB}$ stain in $4 \%$ acetic acid $(\mathrm{pH}=3.5)$ for 5 min. Spermatozoa with the dark blue chromatin $\left(\mathrm{AB}^{+}\right)$were considered as abnormal and spermatozoa with the light blue chromatin $\left(\mathrm{AB}^{-}\right)$as normal spermatozoa [18].

\section{Toluidine blue (TB)}

Toluidine blue (TB) is a basic dye that determines sperm nuclear chromatin integrity via binding to phosphate groups of DNA strands. For this staining, first, the smear slides were rinsed with distilled water, and then hydrolyzed with the $0.1 \mathrm{~N} \mathrm{HCl}$ at $4{ }^{\circ} \mathrm{C}$ for $5 \mathrm{~min}$. After washing in distilled water, the slides were stained with $5 \%$ TB in the $50 \%$ citrate phosphate buffer $(\mathrm{pH}=3.5)$. Finally, spermatozoa heads with the light blue were scored as normal chromatin condensation ( $\left.\mathrm{TB}^{-}\right)$and spermatozoa heads with the dark blue were considered as abnormal $\left(\mathrm{TB}^{+}\right)$[18].

\section{Morphological evaluation of sperm}

Papanicolaou staining was performed to evaluate the sperm morphology. In brief, the smear slides were washed with distilled water for $3 \mathrm{~min}$ and then stained by hematoxylin for $5 \mathrm{~min}$. After washing in distilled water, the slides were dipped in acid alcohol, washed by running water for 3 min, and dipped in $96 \%$ alcohols I and II for $15 \mathrm{sec}$. In the next step, the slides were stained in the OG6 for $5 \mathrm{~min}$ and then with $96 \%$ alcohols I and II for $15 \mathrm{sec}$. After that, the slides were stained with EA 50 for $5 \mathrm{~min}$ and followed by $96 \%$ alcohols I and II for $15 \mathrm{sec}$ and $100 \%$ alcohol for $1 \mathrm{~min}$. Finally, the slides were cleared with xylene and mounted with Entellan (Merck, Germany). After imaging with Olympus (BX51, Japan) light microscope at $\times 1000$ magnification objective lenses (UPlan FI, Japan), normal and abnormal forms of sperm morphology were determined [31].

\section{RNA extraction and $c D N A$ synthesis}

To extract total RNA from the testis and epididymis (Parstous Corporation, Iran) according to the manufacturer's instructions, after mincing tissues into small pieces, tissue homogenization was done in $750 \mu \mathrm{l}$ of RL solution at room temperature for $5 \mathrm{~min}$. Next, after adding $150 \mu \mathrm{l}$ of chloroform, centrifugation was performed for 12 min at $4{ }^{\circ} \mathrm{C}$. Then, $400 \mu \mathrm{l}$ of upper phase was transferred into a new tube and an equal volume of $70 \%$ ethanol was also added to the mixture and centrifuged at $4{ }^{\circ} \mathrm{C}$ for $1 \mathrm{~min}$. In the next step, $700 \mu \mathrm{l}$ and $500 \mu \mathrm{l}$ of PW were also added, respectively, and centrifuged for $2 \mathrm{~min}$ at $4{ }^{\circ} \mathrm{C}$. Finally, $50 \mu \mathrm{l}$ of diethylpyrocarbonate (DEPC) water was added and centrifuged for $1 \mathrm{~min}$ at $4{ }^{\circ} \mathrm{C}$ to elute RNA from the column. The quantity of total RNA was checked by the Nanodrop spectrophotometer (BioTek, Epoch Microplate Spectrophotometer UV-Vis, USA), (ratio A260/A280 nm) and 1\% 
agarose gel for visualization of $18 \mathrm{~S}$ and $28 \mathrm{~S}$ ribosomal bands. To synthesize cDNA, a cDNA synthesis kit (Parstous Corporation, Iran) was used. In brief, in accordance with the manufacturer's protocol, $0.5 \mu$ l of RNA was reverse transcribed with $1 \mu$ of oligo (dt) and $8.5 \mu \mathrm{l}$ of DEPC water. Then, the mixture was incubated at $65{ }^{\circ} \mathrm{C}$ for 5 min and immediately chilled on ice. Afterward, $10 \mu \mathrm{l}$ of RT-premix was added (volume reaction $=20 \mu \mathrm{l}$ ) and incubated at $25^{\circ} \mathrm{C}$ for $10 \mathrm{~min}$, followed by another 60 min at $50{ }^{\circ} \mathrm{C}$, and then the reaction was stopped by heating at $70{ }^{\circ} \mathrm{C}$ for $10 \mathrm{~min}$. Finally, the cDNA samples were stored at $-70{ }^{\circ} \mathrm{C}$.

\section{Real-time polymerase chain reaction (PCR)}

The Real-time PCR was performed in a Step one plus System Thermal Cycler (Applied Biosystems, USA) by using SYBER Green/ROX master mix (Parstous Corporation, Iran). According to the manufacturer's protocols, the volume of each reaction was $20 \mu \mathrm{l}$ consisting of $10 \mu \mathrm{l}$ of master mix, $1 \mu \mathrm{l}$ of each of the forward and the reverse primers (Table 1), $7.1 \mu \mathrm{l}$ sterilized D.W water, $0.4 \mu \mathrm{l}$ Rox dye, and $0.5 \mu \mathrm{l}$ of cDNA. All reactions were run in duplicate for CatSper 1, CatSper 2, and Glyceraldehyde 3-phosphate dehydrogenase (GAPDH) as an internal control. The PCR amplification conditions were as follows: pre-denaturing at $94^{\circ} \mathrm{C}$ for 10 minutes followed by 35 cycles of a three-phase PCR (denaturation at $95^{\circ} \mathrm{C}$ for $30 \mathrm{sec}$, annealing at $60{ }^{\circ} \mathrm{C}$ for $1 \mathrm{~min}$, and extension at $72{ }^{\circ} \mathrm{C}$ for $30 \mathrm{sec}$ ). The relative gene expression was calculated by using the comparative $\mathrm{CT}$ method.

Table 1

Primers used for Real-time PCR

\begin{tabular}{|c|c|c|c|}
\hline $\begin{array}{c}\text { Gene } \\
\text { temperature }\left({ }^{\circ} \mathrm{C}\right)\end{array}$ & Primer sequences & $\begin{array}{l}\text { Product size } \\
\quad \text { (bp) }\end{array}$ & Annealing \\
\hline CatSper 1 & $\begin{array}{l}\text { 5'-ACC AGG TTG AGG AAG ATG AAG T-3'(R) } \\
\text { 5'-TTT ACC TGC CTC TTC CTC TTC T-3'(F) }\end{array}$ & 227 & 59 \\
\hline CatSper 2 & $\begin{array}{l}\text { 5'-ACC AAT GAT CCA AGG TGA AGA-3' (R) } \\
\text { 5'-GGG TGC TGA GGT CTC TCA AAC-3'(F) }\end{array}$ & 261 & 59 \\
\hline $\mathrm{GAPDH}^{\mathrm{a}}$ & $\begin{array}{l}\text { 5'-CTGTAGCCATATTCATTGTCATACCA-3'(R) } \\
\text { 5'-AACTCCCATTCTTCCACCTTTG-3'(F) }\end{array}$ & 385 & 59 \\
\hline
\end{tabular}

aGAPDH: Glyceraldehyde 3-phosphate dehydrogenase.

\section{Sperm immunohistochemistry staining of CatSper 1 and CatSper 2 proteins}

Immunohistochemistry technique was applied on sperm smear. First, the smear slides were rinsed in the phosphate buffer saline solution (PBS) (pH 7.4) three times for 15 $\min$. Antigen retrieval was carried out by heating the slides in the buffer Tris/Ethylene 
diamine tetraacetic acid (EDTA) solution $\mathrm{pH} 9.0$ at $100^{\circ} \mathrm{C}$ for $30 \mathrm{~min}$. After washing in PBS, the endogenous peroxidase activity was quenched by incubating the slides with $3 \% \mathrm{H}_{2} \mathrm{O}_{2}$ in methanol for $20 \mathrm{~min}$ and then washing repeatedly with PBS and blocked with $1 \%$ BSA for $30 \mathrm{~min}$. Subsequently, the slides were incubated with CatSper 1 (D-17: sc-21180) and CatSper 2(L-17: sc-83119) (Santa Cruz Biotechnology, USA) polyclonal primary antibodies (mouse antigoat CatSper antibodies separately at a 1:50 dilution) for overnight at $4{ }^{\circ} \mathrm{C}$, rinsed three times with PBS, and incubated with donkey anti-goat HRP conjugated polyclonal secondary antibody (AbD Serotec, USA) diluted to $1: 200$ for 2 hours at $37^{\circ} \mathrm{C}$. After washing with PBS, the slides were immersed with $0.03 \%$ of 3, 3-diaminobenzidine (DAB) in PBS buffer containing $0.01 \% \mathrm{H}_{2} \mathrm{O}_{2}$ for $15 \mathrm{~min}$, as chromogen. Following washing in running and distilled water, the slides were dehydrated, cleared in xylene, and mounted with Entellan (Merck, Germany). Microscopic images were taken using a light microscope equipped with a high-resolution camera (BX51, Olympus, Japan) with a magnification of $\times 1000$ and objective lens (UPlan FI, Japan). After taking photomicrographs, the different intensities of staining in the sperm were evaluated semi-quantitatively with grading scores as follows: + (weak),,++ (moderate), +++ (strong), and (very strong) ++++ .

\section{Immunohistochemistry detection of CatSper 1 and CatSper 2 in testis}

Immunohistochemistry detection of CatSper 1 and CatSper 2 proteins in the testis tissues was also performed according to the procedure as described previously above [20].

\section{Statistical analysis}

All statistical analyses were done using SPSS software (v.11). The results of immunohistochemistry staining were evaluated by Mann-Whitney non-parametric test while the results of sperm parameters and Real-time PCR were analyzed using by T independent. During the analysis, a p-value $<0.05$ was considered statistically significant.

\section{RESULTS}

\section{Effects of hypothyroidism on chromatin quality}

Table 2 shows the results of sperm morphology and chromatin quality between groups. In $\mathrm{AB}$ staining, the percentages of dark blue stained (abnormal spermatozoa) spermatozoa in the hypothyroid group increased significantly compared to the control group $(\mathrm{P}<0.05)$ (Fig. 1a). According to the TB staining, a significant increase was 


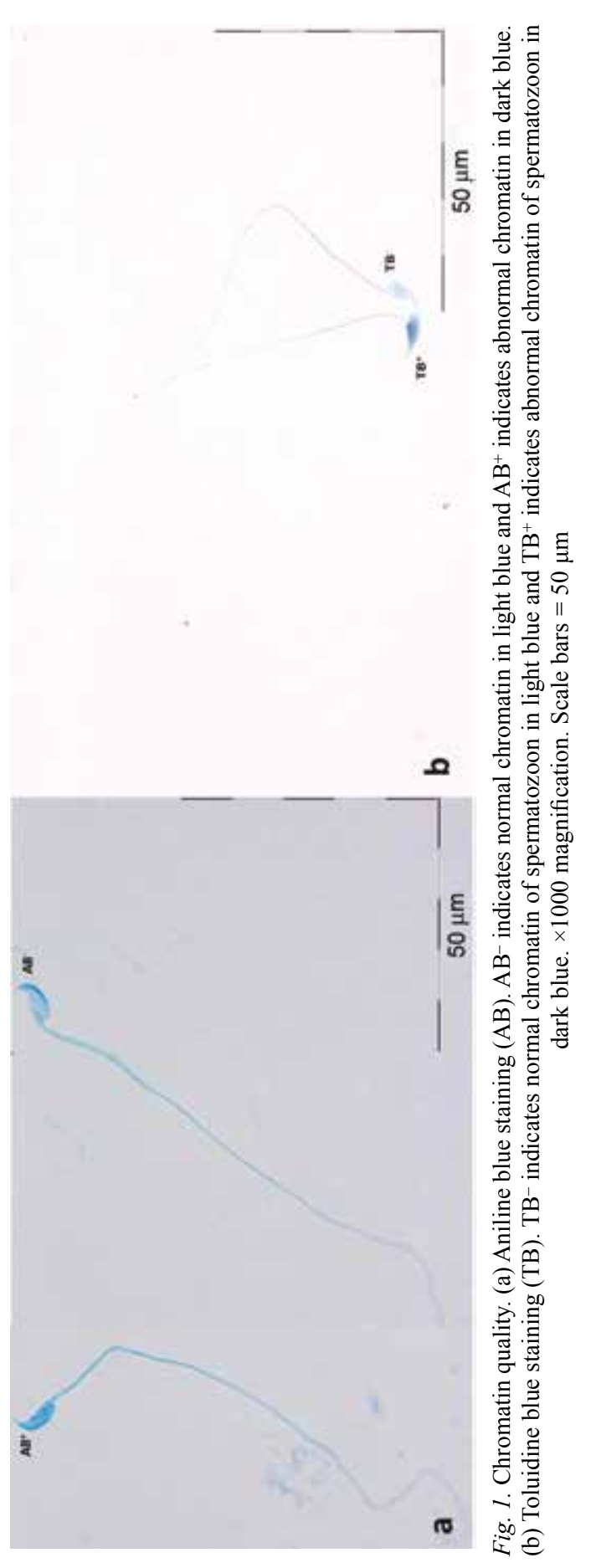

Acta Biologica Hungarica 69, 2018 
observed in the percentage of abnormal spermatozoa (dark blue stained) in the hypothyroid group in comparison with the control group $(\mathrm{p}<0.05)$ (Fig. 1b).

\section{Effects of hypothyroidism on sperm morphology}

In the results of Papanicolaou staining, we found a significant decline in the percentage of spermatozoa with normal morphology in the hypothyroid group compared to the control group $(\mathrm{p}<0.05)$ (Figs 2, Table 2). The microscopic assessment showed different forms of morphological defects in the head, neck, and tail of spermatozoa, particularly in the hypothyroid group.

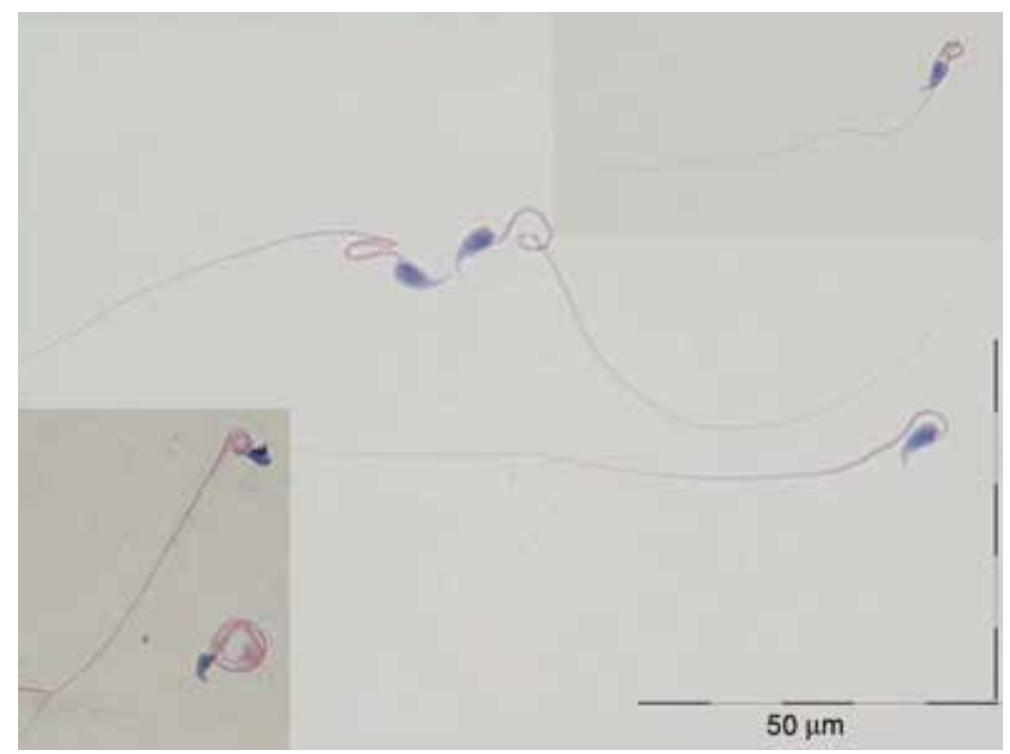

Fig. 2. Papanicolaou staining shows different forms of morphological abnormalities in spermatozoa. $\times 1000$ magnification. Scale bar $=50 \mu \mathrm{m}$

Table 2

Effect of hypothyroidism on sperm morphology and chromatin condensation

\begin{tabular}{|l|c|c|}
\hline \multicolumn{1}{|c|}{ Variables } & Control & Hypothyroid \\
\hline AB (\%) & $21 \pm 2.738$ & $48 \pm 3.897^{\mathrm{a}}$ \\
\hline TB (\%) & $25 \pm 1.581$ & $45 \pm 3.191^{\mathrm{a}}$ \\
\hline Normal sperm (\%) & $90 \pm 3.162$ & $51 \pm 3.082^{\mathrm{a}}$ \\
\hline
\end{tabular}

$\mathrm{AB}$ - aniline blue and TB - toluidine blue staining.

aRepresents significant difference between hypothyroid and control groups p-value $<0.05$. Data are presented as mean $\pm \mathrm{SD}$. 


\section{Effects of hypothyroidism on CatSper 1 and CatSper 2 mRNA levels}

Real-time PCR results showed that the CatSper1 and 2 mRNA levels decreased significantly in the epididymis of the hypothyroid group compared with the control group $(\mathrm{p}<0.001)$ (Figs 3a, 3b). Moreover, CatSper 1 and CatSper 2 mRNA levels in the testis of the hypothyroid group showed a significant decrease compared to that of the control group $(p<0.001)$. Besides, no significant difference was seen in the expression levels of CatSper 1 and CatSper 2 genes in the epididymis and testis (Figs $3 \mathrm{c}, 4 \mathrm{~d})$.

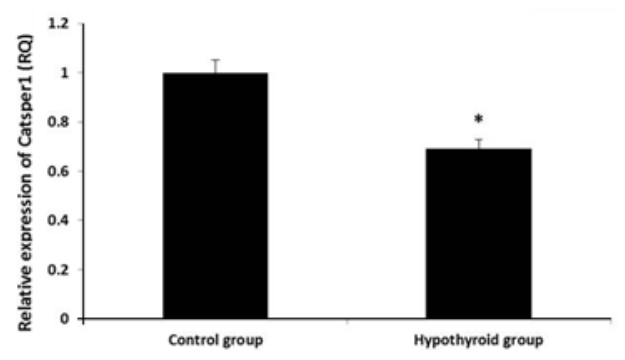

a

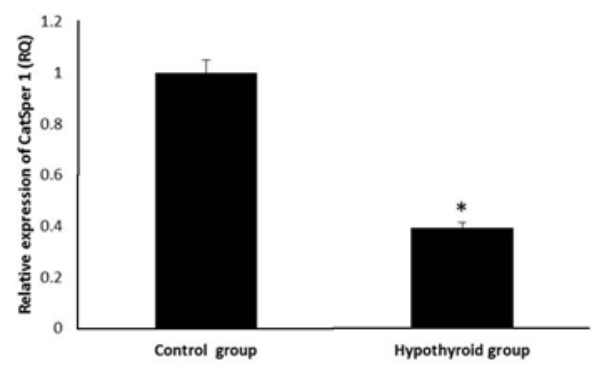

C

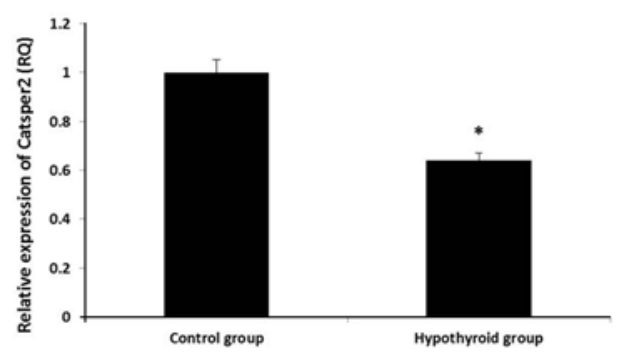

b

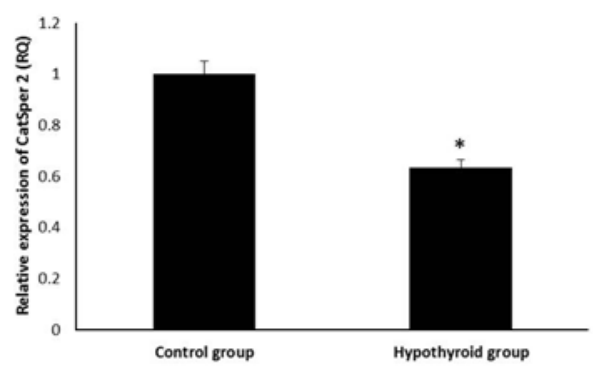

d

Fig. 3. Effect of hypothyroidism on CatSper mRNA levels. (a, b) CatSper 1 and 2 in epididymis, (c, d) CatSper1 and 2 in testis of the hypothyroid group compared to the control group. Values are expressed as mean $\pm \mathrm{SD}$. *Significant differences compared with control group $(\mathrm{p}<0.001)$. RQ $=$ Relative quantification

\section{Effects of hypothyroidism on immunoreactions of CatSper proteins}

The immunohistochemistry detection of CatSper 1 and CatSper 2 proteins was performed on the mouse sperm. Positive immunoreactivity of CatSpers is shown in brown (Fig. 4a-d). The findings revealed that CatSper proteins are distributed throughout the head and the flagellum of sperm; however, the intensity of staining in middle piece of sperm in all groups was higher than in the head and tail of the sperm. The intensity of immunoreactivity for CatSper 1 and CatSper 2 in the hypothyroid mice significantly decreased in comparison to the control mice $(p<0.001)$ (Fig. 5). 


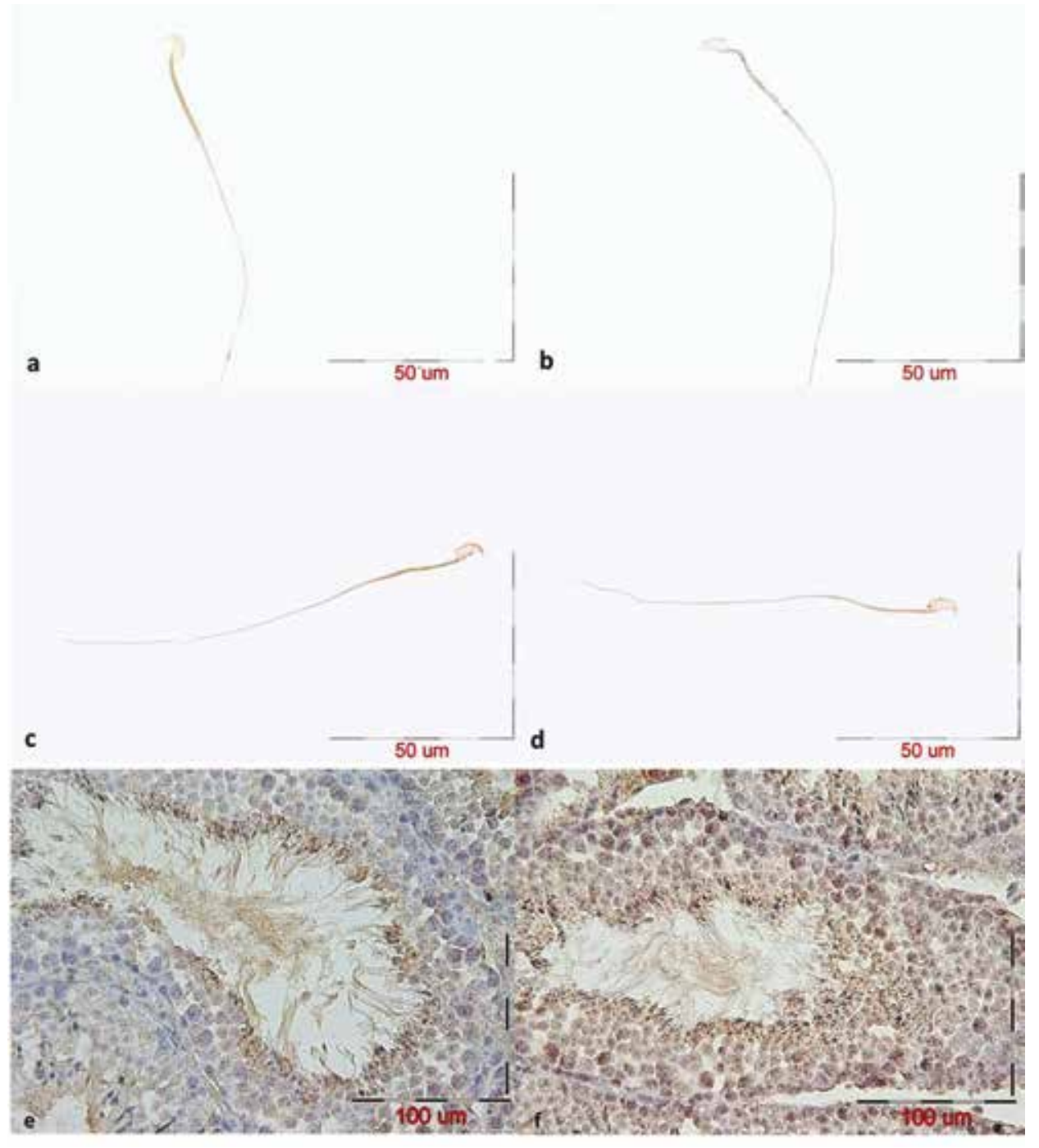

Fig. 4. Photomicrographs show immunoreactivity of CatSper 1 and CatSper 2 proteins in the epididymal sperm and the testis tissue. Positive immunoreaction was shown in different grades of brown color. (a, b) Catsper 1, control and hypothyroid groups, respectively. (c, d) Catsper 2 control and hypothyroid groups, respectively. (e) Catsper 1 and (f) Catsper 2 on testis tissue. Scale bar $=50$ and $100 \mu \mathrm{m}$

Findings of immunohistochemistry were in agreement with CatSper genes expression. No remarkable changes in the intensity of immunoreactivity were observed between the head and tail of the control and the hypothyroid groups. Besides, there was no particular difference between the intensity of immunoreactivity of CatSper 1 and CatSper 2 proteins. 


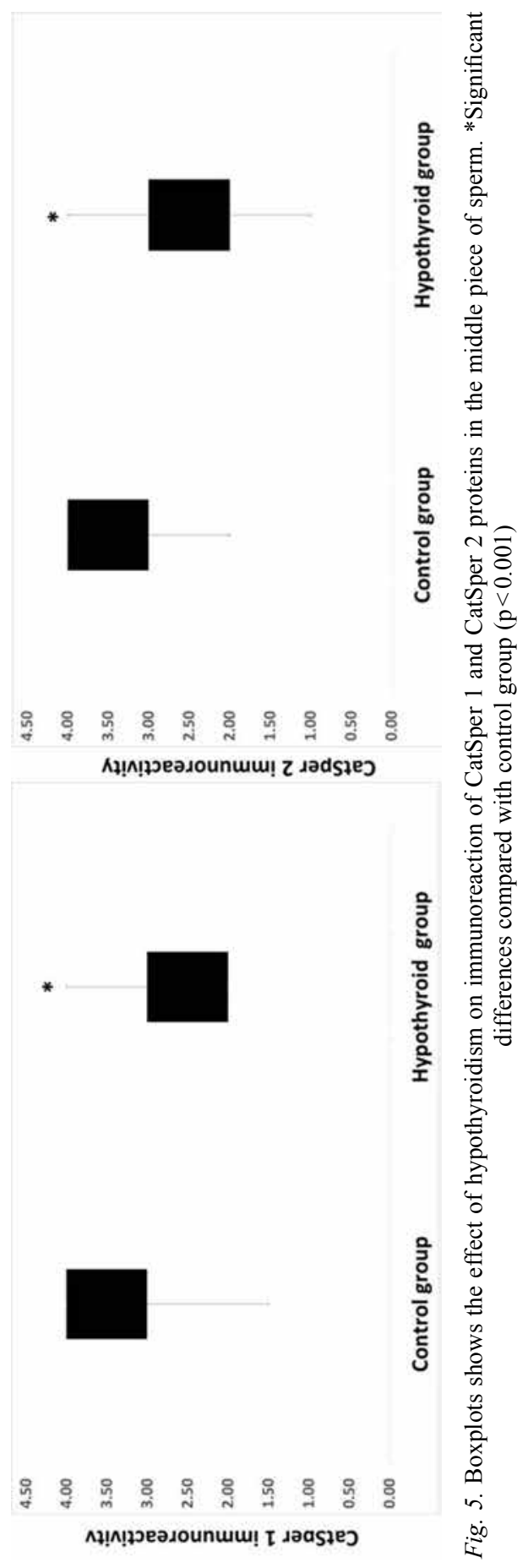

Acta Biologica Hungarica 69, 2018 
Also, the immunohistochemical detection of CatSper 1 and CatSper 2 proteins was done in the testis tissue. Positive immunostaining of both CatSper proteins is shown in brown. The intensity of CatSper 1 and CatSper 2 immunoreactivities was identical and predominantly detected in the spermatids and sperm cell groups in the testis sections (Fig. 4e-f).

\section{DISCUSSION}

It is well documented that testis is one of the major target organs for the thyroid hormones. These hormones play pivotal roles in the testis development, differentiation, and function $[9,10,41]$. Many studies have reported that hypothyroidism causes morphological abnormalities in sperm and reduces the progressive forward motility of the sperm $[14,17,23,42]$. In the present work, we assessed the effects of experimental hypothyroidism on the sperm morphology, sperm chromatin quality, and the expression of CatSper 1 and CatSper 2 genes. Following hypothyroidism in the present study, morphological abnormalities of spermatozoa increased significantly. In accordance with our findings, the morphological deformities of sperm in the tail region of hypothyroid and hyperthyroid men have been reported [37]. Moreover, inconsistent with our results, several experiments have shown that administration of methamphetamine, gold nanoparticles, and acrylamide leads to a decrease in the sperm normal morphology [22, 26, 31]. To our knowledge, the present study was the first report that showed the relationship between the abnormal sperm chromatin quality and hypothyroidism. Meanwhile, regarding the TB staining, we found a significant increase in the percentage of abnormal chromatin spermatozoa between the hypothyroid and the control groups. Our findings also revealed that the rate of $\mathrm{AB}^{+}$spermatozoa increased in the hypothyroid group compared to the control group. Thus, it can be said that hypothyroidism has a negative impact on the quality of sperm chromatin condensation. Our results are in accordance with a research that showed diabetes adversely affects sperm chromatin quality [18]. Similar to our findings, Bakhtiari et al. and Roodbari et al. showed that ibuprofen and cyclophosphamide cause a significant reduction in sperm chromatin $[4,30]$. In another study, Heidari et al. reported that varicocele increases sperm DNA damage [11]. CatSper as one of the most critical cation channel is necessary for hyperactivated sperm motility [25]. Nikpoor et al. has reported a decrease in CatSper expression in subfertile patients with defective sperm motility [24]. Genetical deletion in any of the four main CatSper genes in mice results in loss of hyperactivated motility and subsequent infertility. Neither Catsper1-null nor Catsper2-null sperm displayed hyperactivated motility [12]. Here, we found a significant reduction in the CatSper 1 and CatSper 2 mRNA levels along with proteins in the hypothyroid groups compared to the control group. Our immunostaining results confirmed the localization of CatSper 1 and CatSper 2 proteins channel in the head, middle piece, and the principal piece of sperm like the other reports in this context. Our data analyses also support those theories. The intensity of immunoreactivity of CatSper 1 and CatSper 2 was strong, especially in the middle piece of sperm flagel- 
lum. These data were partially in conjunction with the downregulation of CatSper 1 and CatSper 2 following Kerack abuse in a mouse model [2]. It is well demonstrated that ROS adversely affects male fertility by changing the sperm morphology, motility, and increased sperm DNA damage [31,38]. Results from several studies have suggested that the increase in ROS in pathological conditions is the possible mechanism of sperm DNA damage [11, 18, 26, 31]. The thyroid hormones are involved in the maintaining the balance between ROS and the intrinsic antioxidant molecules in many tissues like testis [17]. It was mentioned earlier that hypothyroidism disturbs the system of the antioxidant defense and also increases the production of ROS in the testis. Meanwhile, due to the limited potential in the enzymatic and non-enzymatic antioxidant defense systems of the testis, it has established that the hypothyroidism has a detrimental impact on the sperm by affecting the morphology and sperm motility [17, 32-34]. Although we could not explain the main mechanism of harmful effects of hypothyroidism on sperm parameters, according to the results and some previous evidence, it can be stated that the hypothyroidism negatively affects some of the main sperm parameters including morphology, motility, and DNA integrity by high amounts of ROS production following the hypothyroidism [4, 11, 18, 20, 30]. However, additional detailed studies can be proposed in this context to validate these findings. Downregulation of CatSper genes in hypothyroid mice, which might be due to the high production of ROS in testis, is likely to inhibit the expression of CatSper genes involved in sperm hypermotility [2]. It has been also reported that treatment with antioxidants such as selenium and vitamin E could improve sperm parameters and up-regulate CatSper 1 and CatSper 2 genes expression in the aging mice and appropriate dose of the vitamin $\mathrm{E}$, as an antioxidant, can increase genes expression in the testis $[20,21]$.

\section{CONCLUSION}

Our study, for the first time, showed that hypothyroidism might probably have detrimental effects on sperm chromatin condensation via the high production of ROS. Moreover, we demonstrated that spermatozoa of hypothyroid mice had a less normal morphology. Also, a negative effect on the expression of CatSper genes was observed.

\section{ACKNOWLEDGEMENTS}

The data used in this paper is from a Ph.D. student thesis (NO: 931752). This work was funded by the Vice-Chancellor for Research of Mashhad University of Medical Sciences, Mashhad, Iran. The authors would like to thank Mrs. F. Motejadded and Mrs. F. Tajik for their technical assistance.

\section{REFERENCES}

1. Alasmari, W., Barratt, C. L., Publicover, S. J., Whalley, K. M., Foster, E., Kay, V., Martins da Silva, S., Oxenham, S. K. (2013) The clinical significance of calcium-signalling pathways mediating human sperm hyperactivation. Hum. Reprod. 28, 866-876. 
2. Amini, M., Shirinbayan, P., Behnam, B., Roghani, M., Farhoudian, A., Joghataei, M. T., Koruji, M. (2014) Correlation between expression of CatSper family and sperm profiles in the adult mouse testis following Iranian Kerack abuse. Andrology 2, 386-393.

3. Anbalagan, J., Sashi, A. M., Vengatesh, G., Stanley, J. A., Neelamohan, R., Aruldhas, M. M. (2010) Mechanism underlying transient gestational-onset hypothyroidism-induced impairment of posttesticular sperm maturation in adult rats. Fertil. Steril. 93, 2491-2497.

4. Bakhtiary, Z., Shahrooz, R., Ahmadi, A., Zarei, L. (2015) Protective effects of ethyl pyruvate on sperm quality in cyclophosphamide treated mice. Iran J. Reprod. Med. 13, 291-296.

5. Canale, D., Agostini, M., Giorgilli, G., Caglieresi, C., Scartabelli, G., Nardini, V., Jannini, E. A., Martino, E., Pinchera, A., Macchia, E. (2001) Thyroid hormone receptors in neonatal, prepubertal, and adult rat testis. J. Androl. 22, 284-288.

6. Chattopadhyay, S., Choudhury, S., Roy, A., Chainy, G. B., Samanta, L. (2010) T3 fails to restore mitochondrial thiol redox status altered by experimental hypothyroidism in rat testis. Gen. Comp. Endocrinol. 169, 39-47.

7. Choudhury, S., Chainy, G. B., Mishro, M. M. (2003) Experimentally induced hypo- and hyper-thyroidism influence on the antioxidant defence system in adult rat testis. Andrologia 35, 131-140.

8. Chung, J. J., Navarro, B., Krapivinsky, G., Krapivinsky, L., Clapham, D. E. (2011) A novel gene required for male fertility and functional CATSPER channel formation in spermatozoa. Nat. Commun. $2,153$.

9. Dittrich, R., Beckmann, M. W., Oppelt, P. G., Hoffmann, I., Lotz, L., Kuwert, T., Mueller, A. (2011) Thyroid hormone receptors and reproduction. J. Reprod. Immunol. 90, 58-66.

10. Gao, Y., Lee, W. M., Cheng, C. Y. (2014) Thyroid hormone function in the rat testis. Front. Endocrinol. (Lausanne) 5, 188

11. Heidari, R., Alizadeh, R., Abbasi, N., Pasbakhsh, P., Hedayatpour, A., Farajpour, M., Khaleghi, M. R., Abbasi, M., Dehpour, A. R. (2015) Do pilea microphylla improve sperm DNA fragmentation and sperm parameters in varicocelized rats? Acta Med. Iran 53, 547-554.

12. Jin, J., Jin, N., Zheng, H., Ro, S., Tafolla, D., Sanders, K. M., Yan, W. (2007) Catsper3 and Catsper4 are essential for sperm hyperactivated motility and male fertility in the mouse. Biol. Reprod. 77 , 37-44.

13. Kirichok, Y., Lishko, P. V. (2011) Rediscovering sperm ion channels with the patch-clamp technique. Mol. Hum. Reprod. 17, 478-499.

14. Krajewska-Kulak, E., Sengupta, P. (2013) Thyroid function in male infertility. Front. Endocrinol. (Lausanne) 4, 174.

15. Krassas, G. E., Papadopoulou, F., Tziomalos, K., Zeginiadou, T., Pontikides, N. (2008) Hypothyroidism has an adverse effect on human spermatogenesis: a prospective, controlled study. Thyroid. 18, 12551259

16. Krassas, G. E., Poppe, K., Glinoer, D. (2010) Thyroid function and human reproductive health. Endocr. Rev. 31, 702-755.

17. Kumar, A., Shekhar, S., Dhole, B. (2014) Thyroid and male reproduction. Indian J. Endocrinol. Metab. 18, 23-31.

18. Mangoli, E., Talebi, A. R., Anvari, M., Pourentezari, M. (2013) Effects of experimentally-induced diabetes on sperm parameters and chromatin quality in mice. Iran J. Reprod. Med. 11, 53-60.

19. Mendeluk, G. R., Rosales, M. (2016) Thyroxin is useful to improve sperm motility. Int. J. Fertil Steril. $10,208-214$.

20. Mohammadi, S., Jalali, M., Nikravesh, M. R., Fazel, A., Ebrahimzadeh, A., Gholamin, M., Sankian, M. (2013) Effects of vitamin-E treatment on CatSper genes expression and sperm quality in the testis of the aging mouse. Iran J. Reprod. Med. 11, 989-998.

21. Mohammadi, S., Movahedin, M., Mowla, S. J. (2009) Up-regulation of CatSper genes family by selenium. Reprod. Biol. Endocrinol. 7, 126.

22. Nazar, M., Talebi, A. R., Hosseini Sharifabad, M., Abbasi, A., Khoradmehr, A., Danafar, A. H. (2016) Acute and chronic effects of gold nanoparticles on sperm parameters and chromatin structure in mice. Int. J. Reprod. Biomed. (Yazd) 14, 637-642. 
23. Nikoobakht, M. R., Aloosh, M., Nikoobakht, N., Mehrsay, A. R., Biniaz, F., Karjalian, M. A. (2012) The role of hypothyroidism in male infertility and erectile dysfunction. Urol. J. 9, 405-409.

24. Nikpoor, P., Mowla, S. J., Movahedin, M., Ziaee, S. A., Tiraihi, T. (2004) CatSper gene expression in postnatal development of mouse testis and in subfertile men with deficient sperm motility. Hum. Reprod. 19, 124-128.

25. Park, E. H., Kim, D. R., Kim, H. Y., Park, S. K., Chang, M. S. (2014) Panax ginseng induces the expression of CatSper genes and sperm hyperactivation. Asian J. Androl. 16, 845-851.

26. Pourentezari, M., Talebi, A., Abbasi, A., Khalili, M. A., Mangoli, E., Anvari, M. (2014) Effects of acrylamide on sperm parameters, chromatin quality, and the level of blood testosterone in mice. Iran J. Reprod. Med. 12, 335-342.

27. Qi, H., Moran, M. M., Navarro, B., Chong, J. A., Krapivinsky, G., Krapivinsky, L., Kirichok, Y., Ramsey, I. S., Quill, T. A., Clapham, D. E. (2007) All four CatSper ion channel proteins are required for male fertility and sperm cell hyperactivated motility. Proc. Natl Acad. Sci. USA 104, 1219-1223.

28. Quill, T. A., Ren, D., Clapham, D. E., Garbers, D. L. (2001) A voltage-gated ion channel expressed specifically in spermatozoa. Proc. Natl Acad. Sci. USA 98, 12527-12531.

29. Ren, D., Navarro, B., Perez, G., Jackson, A. C., Hsu, S., Shi, Q., Tilly, J. L., Clapham, D. E. (2001) A sperm ion channel required for sperm motility and male fertility. Nature 413, 603-609.

30. Roodbari, F., Abedi, N., Talebi, A. R. (2015) Early and late effects of ibuprofen on mouse sperm parameters, chromatin condensation, and DNA integrity in mice. Iran J. Reprod. Med. 13, 703-710.

31. Sabour, M., Khoradmehr, A., Kalantar, S. M., Danafar, A. H., Omidi, M., Halvaei, I., Nabi, A., Ghasemi-Esmailabad, S., Talebi, A. R. (2017) Administration of high dose of methamphetamine has detrimental effects on sperm parameters and DNA integrity in mice. Int. J. Reprod. Biomed. (Yazd) $15,161-168$.

32. Sahoo, D. K., Roy, A. (2012) Compromised rat testicular antioxidant defence system by hypothyroidism before puberty. Int. J. Endocrinol. 2012, 637825.

33. Sahoo, D. K., Roy, A., Bhanja, S., Chainy, G. B. (2008) Hypothyroidism impairs antioxidant defence system and testicular physiology during development and maturation. Gen. Comp. Endocrinol. 156, 63-70.

34. Sasikumar, S., Dakshayani, D. (2013) Assessment of sperm DNA integrity by Toluidine blue staining technique in infertile patients and its relation to cryopreservation. Int. J. Curr. Microbiol. App. Sci. 2 , 280-292.

35. Shukla, K. K., Mahdi, A. A., Rajender, S. (2012) Ion channels in sperm physiology and male fertility and infertility. J. Androl. 33, 777-788.

36. Singh, A. P., Rajender, S. (2015) CatSper channel, sperm function and male fertility. Reprod. Biomed. Online 30, 28-38.

37. Singh, R., Hamada, A., Agarwal, A. (2011) Thyroid hormones in male reproduction and fertility. Open Reprod. Sci. J. 3, 98-104.

38. Talebi, A. R., Mangoli, E., Nahangi, H., Anvari, M., Pourentezari, M., Halvaei, I. (2014) Vitamin C attenuates detrimental effects of diabetes mellitus on sperm parameters, chromatin quality and rate of apoptosis in mice. Eur. J. Obstet. Gynecol. Reprod. Biol. 181, 32-36.

39. Talebi, A. R., Vahidi, S., Aflatoonian, A., Ghasemi, N., Ghasemzadeh, J., Firoozabadi, R. D., Moein, M. R. (2012) Cytochemical evaluation of sperm chromatin and DNA integrity in couples with unexplained recurrent spontaneous abortions. Andrologia 44 Suppl. 1, 462-470.

40. Ulisse, S., Rucci, N., Piersanti, D., Carosa, E., Graziano, F. M., Pavan, A., Ceddia, P., Arizzi, M., Muzi, P., Cironi, L., Gnessi, L., D’Armiento, M., Jannini, E. A. (1998) Regulation by thyroid hormone of the expression of basement membrane components in rat prepubertal Sertoli cells. Endocrinology 139, 741-747.

41. Wagner, M. S., Wajner, S. M., Maia, A. L. (2008) The role of thyroid hormone in testicular development and function. J. Endocrinol. 199, 351-365.

42. Wajner, S. M., Wagner, M. S., Maia, A. L. (2009) Clinical implications of altered thyroid status in male testicular function. Arq. Bras. Endocrinol. Metabol. 53, 976-982. 